Research Paper

\title{
Effectiveness of Acceptance and Commitment Therapy on Anxiety, Cognitive Avoidance, and Empathy of Cou- ples Visiting Counseling Centers in Ahvaz City, Iran
}

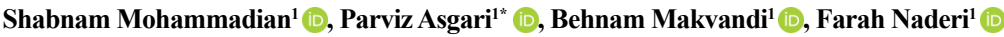 \\ 1. Department of Psychology, Faculty of Humanities, Ahvaz Branch, Islamic Azad University, Ahvaz, Iran
}

\begin{tabular}{|l|l|l}
\hline $\begin{array}{c}\text { Use yur devic to scan } \\
\text { and read the article online }\end{array}$ & $\begin{array}{l}\text { Cittation Mohammadian Sh, Asgari P, Makvandi B, Naderi F. Effectiveness of Acceptance and Commitment Therapy on } \\
\text { Anxiety, Cognitive Avoidance, and Empathy of Couples Visiting Counseling Centers in Ahvaz City, Iran. Journal of Research \& }\end{array}$ \\
Health. 2021; 11(6):393-402. http://dx.doi.org/10.32598/JRH.11.6.1889.1
\end{tabular}

(i) (3)

Article info:

Received: 05 Apr 2021

Accepted: 13 Jun 2021

Publish: 01 Dec 2021

Keywords:

Acceptance and Commitment Therapy (ACT), Anxiety, Cognitive psychology, Empathy

\section{A B STRACT}

Background: Anxiety can reduce the couples' self-confidence and damage their mental health. The present study aimed to investigate the effectiveness of Acceptance and Commitment Therapy (ACT) on anxiety, cognitive avoidance, and empathy among couples visiting counseling centers in Ahvaz City, Iran, in 2020.

Methods: The research method was quasi-experimental with a pre-test, post-test design, followup, and a control group. The statistical population consisted of all couples with low marital adjustment who were referred to the psychological centers of Ahvaz in 2019. Using a convenience sampling method, 30 participants were selected and randomly divided into experimental and control groups ( $\mathrm{n}=15$ per group). The research instruments included the symptom checklist-90revised, the cognitive avoidance questionnaire, and the basic empathy scale. The experimental group underwent eight 90-min sessions (one session per week) of ACT, and the control group did not receive any intervention. The follow-up was performed after 45 days. Repeated-measures ANOVA was used to analyze the data in SPSS

Results: ACT effectively decreased anxiety and cognitive avoidance and increased empathy among couples in the experimental group $(\mathrm{P}<0.001)$. The Mean \pm SD pre-test and post-test scores of anxiety in the experimental group were $23.33 \pm 2.89$ and $18.93 \pm 3.36$, respectively, which decreased compared to the post-test mean score (24.27 \pm 2.96$)$ of the control group.

Conclusion: ACT decreased anxiety and cognitive avoidance and significantly increased empathy in married individuals. ACT can improve empathy in couples involved in marital conflicts.

\footnotetext{
* Corresponding Author:

Parviz Asgari, PhD.

Address: Department of Psychology, Faculty of Humanities, Ahvaz Branch, Islamic Azad University, Ahvaz, Iran.

Phone: +98 (61) 33329200

E-mail: paskarii45@gmail.com
} 


\section{Introduction}

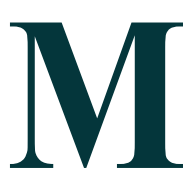

arriage has a significant impact on people's mental health. If marital life fails to meet the needs of couples, not only will mental health be compromised, but it will also have negative and sometimes irreversible consequences [1]. Couples' marital dissatisfaction and emotional dissociation drive them to divorce or apply for divorce [2, 3]. Couples with inefficient relationships may need to learn proper skills to express their emotions and effectively solve their problems. Maladaptive interactions may result from a lack of skills, and many couples are disappointed because their needs are not met. When one of the couples is unhappy in their relationship, a self-sustaining cycle is set in motion that tends to intensify the problem. In the cognitive-behavioral facets of emotion, this cycle can be seen in couples' discussions when the husband says something negative and the wife often reacts negatively. When couples act negatively toward each other, they also think negatively about each other. They may have emotional salience with few negative emotions toward their spouse. Bad feelings increase the probability of negative attitudes and thoughts [4].

Anxiety is a common issue among couples that harms their marital life [5]. Anxiety is described as an uncomfortable state of emotional arousal that people feel. It is a normal response to dangerous circumstances. Also, it is a sign that alerts people to potential danger and helps them take the appropriate precautions to prevent it. Almost all people, at some stage in their lives, will experience anxiety. Anxiety can lower a couple's selfesteem and, as a result, harms their mental health [6].

Cognitive avoidance is another common disorder among married couples who have problems. Cognitive avoidance is a term that refers to a variety of strategies for changing people's minds in social situations [7]. It entails actions to deny or downplay the crisis and its consequences or accept the situation because it cannot be changed. Rumination, catastrophizing, reevaluation, and re-focus on plans are all examples of cognitive avoidance [8]. According to cognitive models, avoidance behaviors with a catastrophic view of events lead to withdrawal. Thought appeasement and substitution, distraction, avoiding threatening stimuli, and turning imaginations into thoughts are some cognitive avoidance strategies. These strategies divert the mind from the topic of concern and lead toward other issues that may be more concerning than the original one. Thought appeasement and avoidance of threaten- ing stimuli do not eliminate disturbing thoughts; instead, they provide fodder for irritating rumination. As an avoidance strategy, thought appeasement could create more mental worries [9].

The standard of a couple's marriage is determined by their empathic relationship [10]. Empathy is defined as understanding and sharing another person's feelings. Understanding the mental state of others is what organizes and regulates a wide range of behaviors. Empathic people focus unselfishly on the experiences of others rather than relying on their experiences [11]. According to research, many factors are related to an individual's personality and statuses, such as genetic factors, gender, learning, and cultural factors, which influence empathy. There is some empathy between couples in a stable marriage, and if one of them lacks the desired creative power, they have difficulty understanding each other's experiences $[12,13]$. Positive feelings and productive relationships with others characterize highly empathic individuals. They also demonstrate a strong ability to listen, communicate feelings, and develop verbal and nonverbal communication skills [14].

Acceptance and Commitment Therapy (ACT) is a relatively new recovery approach with main clinical processes that vary from conventional cognitive-behavioral therapy [15]. Its fundamental principles are 1) acceptance or the tendency to experience discomfort or other distressing occurrences without participating in harnessing them, and 2) values-guided behavior or engagement coupled with the urge to have positive personal goals rather than removing unwanted interactions that contribute to healthy functioning while dealing with other nonverbal dependencies. ACT includes exposure-based interactions and drills, as well as linguistic metaphors and approaches like mental care preparation [16]. Mirzaeidoostan et al. [17] reported that ACT was effective in reducing death anxiety and improving the mental health of patients with Human Immunodeficiency Virus (HIV). Also, they reported that ACT as a complementary therapy improves psychological symptoms. Haji Eghrari et al. [18] reported that ACT significantly reduced behavioral inhibition and cognitive-behavioral avoidance in women with generalized anxiety disorder.

This therapeutic approach increases one's mental acceptance of mental experiences (thoughts, feelings) while decreasing ineffective regulating behaviors. It helps the patient prevent or monitor any behavior exacerbating ineffective, counterproductive, or undesirable mental experiences. Under this therapy, people become 
aware of their psychological consciousness in the present moment. The patients are advised in the fourth stage to reduce the undue emphasis on self-image or personal narratives (such as becoming a victim of other conditions) that they have produced in their minds. In the fifth step, the patients are assisted in recognizing their core personal beliefs, identifying them explicitly, and translating them into concrete therapeutic objectives (value methodology). The final stage is to encourage the patients to take committed action, which is described as behavior based on predetermined goals and values, as well as embracing mental experiences. Depressing, obsessive, and trauma-related feelings, as well as fears, can be part of these experiences [19]. According to Moradzadeh and Pirkhaefi [20], ACT improves marital satisfaction and cognitive versatility in married employees. Sa,adatmand et al. [21] examined the effect of ACT on marital satisfaction and couple empathy. Evaluation and explanation of ACT on psychological characteristics, such as anxiety, cognitive avoidance, and empathy of couples, are among the most important innovations of the present study.

Given the importance of mental health and the impact of anxiety, cognitive avoidance, and empathy in marital life, the present study sought to investigate the ACT effect on anxiety, cognitive avoidance, and empathy among couples visiting counseling centers in Ahvaz City, Iran.

\section{Methods}

The study design was quasi-experimental. The study population consisted of all married people with low marital adjustment who were referred to the counseling and psychological centers of Ahvaz in 2020. Using a convenience sampling method, 30 participants were selected and randomly divided into experimental and control groups. Fifteen participants involved in marital conflicts were included in each group calculated by G*Power software [22]. The samples should have a lower score than the cut-off point in the marital adjustment test, be 25-45 years old, passed more than two years of marital life, and be under no medication and or any type of treatment intervention during the study. The samples were excluded after the occurrence of stressful events, such as divorce and the death of relatives, the absence of more than two treatment sessions, and reluctance to continue the treatment process.

To conduct this study, first, the author visited dedicated counseling and psychology clinics in Ahvaz and talked to the authorities about the research proj- ect. They were justified and asked to refer the couples with low marital adjustment to the researcher. During interviews, low marital adjustment and high intrapersonal problems were the most common complaints of the couples when visiting counseling centers. Following the necessary examinations, 30 eligible individuals were selected to participate in the study. After selecting the participants, the experimental group received eight 90-min sessions (one session per week) of ACT. No treatment intervention was offered to the control group. They were placed on the waiting list to receive the treatment at the end of the study. The follow-up was performed after 45 days. The ACT intervention program sessions were conducted at Ahvaz Psychological Counseling Center by a researcher who had received specialized courses and workshops. For ethical considerations, the researchers obtained written consent from the participants for participation in the research. The study was approved by the Ethics Committee of Islamic Azad University, Ahvaz Branch (Code: IR.IAU. AHVAZ.REC.1399.019).

\section{Research instruments}

The Symptom CheckList-90-Revised (SCL-90-R)

Leonard R. Derogatis developed the symptom checklist-90-revised (SCL-90-R). It is a self-report instrument containing 90 items and designed to measure 9 current psychiatric symptoms, as well as psychological distress. The SCL-90-R subscales assess the following psychiatric symptoms: somatization, obsessive-compulsive disorder, interpersonal sensitivity, depression, anxiety, hostility, phobic anxiety, paranoid ideation, and psychoticism. Each item is scored on a 5-point scale: $1=$ not at all, $2=$ little, $3=$ some, $4=$ very, $5=$ severe [23]. Akhavan Abiri and Shairi [24] reported a Cronbach $\alpha$ coefficient of 0.88 for the whole questionnaire. In the present study, the Cronbach $\alpha$ coefficient was 0.87 for the scale.

\section{Cognitive Avoidance Questionnaire (CAQ)}

The Cognitive Avoidance Questionnaire (CAQ) is a self-report scale developed by Sexton and Dugas [25]. It consists of 25 items that measure cognitive avoidance from various aspects: appeasement of anxious thoughts, the substitution of anxious thoughts with positive ones, using distraction to interrupt the process of worrying, avoiding situations and activities that activate anxious thoughts, and turning mental images into verbal thoughts. CAQ is scored on a 5-point Likert scale from very untrue $=1$ to very true $=5$. The total score is 
Table 1. A Summary of Acceptance and Commitment Therapy (ACT) sessions [30]

\begin{tabular}{cl}
\hline Sessions & \multicolumn{1}{c}{ Contents } \\
\hline 1 & Introducing members, mentioning group regulations and objectives, and introducing the course \\
2 & $\begin{array}{l}\text { Introducing some concepts of acceptance and commitment therapy, including the experience of avoidance, integration, } \\
\text { and mental acceptance }\end{array}$ \\
3 & $\begin{array}{l}\text { Implementing acceptance and commitment therapy techniques, such as cognitive isolation, psychological awareness, } \\
\text { and self-visualization }\end{array}$ \\
4 & $\begin{array}{l}\text { Teaching treatment techniques, emotional awareness, wise awareness (self-victim metaphor) } \\
\text { training }\end{array}$ \\
6 & $\begin{array}{l}\text { Teaching treatment techniques of personal values and clarifying values, teaching emotion regulation } \\
\text { (Bad cup metaphor) }\end{array}$ \\
7 & $\begin{array}{l}\text { Teaching treatment techniques of personal values and committed action and promoting interpersonal efficiency (chess } \\
\text { scene metaphor) }\end{array}$ \\
\hline 8 & $\begin{array}{l}\text { Reviewing and practicing the trained treatment techniques with an emphasis on regulating emotions and a sense of } \\
\text { meaningfulness in real world }\end{array}$ \\
\hline
\end{tabular}

obtained by adding the scores of each item, ranging between 25 and 125. Lower scores indicate low cognitive avoidance and higher scores high cognitive avoidance. Aghajani et al. [26] reported the Cronbach $\alpha$ coefficient of 0.86 for the questionnaire. In the present study, the Cronbach $\alpha$ coefficient was 0.79 for the questionnaire.

\section{Basic Empathy Scale (BES-A)}

Batson developed the Basic Empathy Scale in adults (BES-A) in 1983. BES-A consists of a list of empathic feelings: empathizing, sympathizing, worrying, being affected, pitying, warmth and intimacy, being kind, and considerate. The participants score their empathic feelings toward their spouses on a 6-point Likert scale from $1=$ never to $6=$ very strongly. The total scores ranged from 8 to 48 [27]. Carre et al. [28] reported the Cronbach $\alpha$ coefficient of 0.86 for the scale, and Farzadi et al. [29] evaluated its reliability as 0.95 . In the present study, the Cronbach $\alpha$ coefficient was 0.87 for the scale.

\section{Intervention program}

The experimental group participated in eight 90-minute sessions of ACT. These sessions were performed once a week based on the practice of ACT of Hayes et al. [30]. Table 1 presents a summary of ACT sessions.

\section{Statistical analyses}

The obtained data were analyzed by descriptive statistics of Mean \pm SD and inferential statistics of repeatedmeasures ANOVA in SPSS software. The significance level of the tests was considered 0.05 .

\section{Results}

Table 2 presents the Mean \pm SD of the pre-test, posttest, and follow-up scores of anxiety, cognitive avoidance, and empathy among the couples in the experimental and control groups.

Before analyzing the data associated with hypotheses, they were examined to confirm the assumptions of repeated-measures ANOVA. The Shapiro-Wilk test was not significant regarding the scores of anxiety, cognitive avoidance, and empathy variables, so the distribution of these variables is normal. In this study, Levene's test of equality of variances was used to examine the homogeneity of variances. The $\mathrm{F}$ value calculated by Levene's test was not significant regarding the variables of anxiety, cognitive avoidance, and empathy in the pre-test, post-test, and follow-up. Therefore, there was no significant difference between the error variances of the two groups. Mauchly's sphericity test also showed that the sphericity assumption was met. Thus, the assumptions for performing the repeated measurement analysis of variance have been observed.

Based on the results of within-group analysis, there was a significant difference between the mean scores of ACT in the pre-test, post-test, and follow-up stages $(\mathrm{P}<0.001)$. The results showed that $53 \%$ of the differences in anxiety, $77 \%$ in cognitive avoidance, and 50\% in empathy were due to the interaction of the three stages of pre-test, post-test, and follow-up. Based on the results of the between-group analysis, the mean scores of anxiety, cognitive avoidance, and empathy were sig- 
Table 2. Mean $\pm S D$ of the study variables in the experimental and control groups in the pre-test, post-test, and follow-up

\begin{tabular}{cccc}
\hline \multirow{2}{*}{ Dependent Variables } & Phases & \multicolumn{2}{c}{ Mean \pm SD } \\
\cline { 3 - 3 } Anxiety & Pre-test & Experimental & Control \\
\hline & Post-test & $23.33 \pm 2.89$ & $23.67 \pm 2.92$ \\
& Follow-up & $18.93 \pm 3.36$ & $24.27 \pm 2.96$ \\
& Pre-test & $19.60 \pm 3.18$ & $24.40 \pm 2.66$ \\
Cognitive avoidance & Post-test & $53.27 \pm 7.52$ & $51.00 \pm 5.90$ \\
& Follow-up & $48.93 \pm 8.07$ & $51.40 \pm 5.98$ \\
Empathy & Pre-test & $47.47 \pm 8.17$ & $51.40 \pm 6.18$ \\
& Post-test & $31.40 \pm 4.27$ & $29.07 \pm 3.15$ \\
& Follow-up & $27.72 \pm 4.33$ & $29.13 \pm 3.02$ \\
& & $28.33 \pm 4.38$ & $29.33 \pm 3.22$ \\
\hline
\end{tabular}

He:

nificantly different in the experimental group and the control group $(\mathrm{P}<0.001)$. The results showed that $72 \%$ of the differences in anxiety, $82 \%$ in cognitive avoidance, and $59 \%$ in empathy were due to group $\times$ time interaction (Table 3 )

The results of the Bonferroni post hoc test for comparison of experimental and control groups are presented in Table 4. The results showed a significant difference between pre-test and post-test in all three variables of anxiety, cognitive avoidance, and empathy $(\mathrm{P}<0.001)$. Thus, the effect of the intervention was con- firmed. There was also a significant difference between pre-test and follow-up in research variables $(\mathrm{P}<0.001)$. In other words, the sustainability of the intervention was confirmed for all variables. On the other hand, the comparison between post-test and follow-up in all three variables showed no significant difference $(\mathrm{P}>0.05)$.

\section{Discussion}

The present study aimed to investigate the effectiveness of ACT on anxiety, cognitive avoidance, and empathy among couples visiting counseling centers

Table 3. Repeated measurement results for the effects of time and interaction time and group

\begin{tabular}{|c|c|c|c|c|c|c|c|}
\hline Variables & Source & SS & df & MS & $\mathbf{F}$ & $\mathbf{P}$ & $\eta^{2}$ \\
\hline & Time & 33.75 & 1 & 33.75 & 32.66 & 0.001 & 0.53 \\
\hline \multirow[t]{3}{*}{ Anxiety } & Group×time & 74.81 & 1 & 74.81 & 72.40 & 0.001 & 0.72 \\
\hline & Error & 28.93 & 28 & 1.03 & & & \\
\hline & Time & 109.35 & 1 & 109.35 & 98.76 & 0.001 & 0.77 \\
\hline \multirow[t]{3}{*}{ Cognitive avoidance } & Groupxtime & 144.15 & 1 & 144.15 & 130.20 & 0.001 & 0.82 \\
\hline & Error & 31 & 28 & 1.10 & & & \\
\hline & Time & 29.40 & 1 & 29.40 & 28.45 & 0.001 & 0.50 \\
\hline \multirow[t]{2}{*}{ Empathy } & Groupxtime & 41.66 & 1 & 41.66 & 40.32 & 0.001 & 0.59 \\
\hline & Error & 28.93 & 28 & 1.03 & & & \\
\hline
\end{tabular}

SS: Sum of Squares; df: Degree of freedom; MS: Mean of Squares; F: F-distribution; $\eta^{2}$ : Eta-squared. 
Table 4. Bonferroni post hoc test for pairwise comparison of the research variables across time series in the experimental groups

\begin{tabular}{|c|c|c|c|c|c|}
\hline Variables & Phase A & Phase B & Mean Difference (A-B) & SE* & $\mathbf{P}$ \\
\hline \multirow{3}{*}{ Anxiety } & Pre-test & Post-test & 1.83 & 0.23 & 0.001 \\
\hline & & Follow-up & 1.50 & 0.26 & 0.001 \\
\hline & Post-test & Follow-up & 0.33 & 0.16 & 0.13 \\
\hline \multirow{3}{*}{ Cognitive avoidance } & Pre-test & Post-test & 2.47 & 0.28 & 0.001 \\
\hline & & Follow-up & 2.70 & 0.27 & 0.001 \\
\hline & Post-test & Follow-up & 0.23 & 0.13 & 0.29 \\
\hline \multirow{3}{*}{ Empathy } & Pre-test & Post-test & 1.80 & 0.22 & 0.001 \\
\hline & & Follow-up & 1.40 & 0.26 & 0.001 \\
\hline & Post-test & Follow-up & 0.40 & 0.16 & 0.06 \\
\hline
\end{tabular}

* Standard Error.

in Ahvaz City. The current study results showed that ACT significantly decreased anxiety and cognitive avoidance and increased empathy among couples in the experimental group. This finding is consistent with the research results of Moradzadeh and Pirkhaefi [20], Khoramnia et al. [31], and Heydari et al. [32]. Khoramnia et al. [31] reported that ACT might be an appropriate psychological intervention for reducing external shame, social anxiety, and difficulty in emotion regulation and its components and helping the individuals improve psychological flexibility. Heydari et al. [32] showed that ACT reduced anxiety and depression in psychiatric center staff.

ACT teaches people how to decrease their experimental avoidance and increase their flexibility and valuesguided action. Acceptance-based behavioral therapy emphasizes the increase in values-guided action. Participants choose those behavioral goals that are more important or valuable to them. ACT is a therapeutic approach that includes both variables of acceptance and change to accept immutable problems and be committed to changing mutable problems and behaviors [33]. This approach recommends couples accept the existing conditions and avoid unnecessary conflicts and fusion with unwanted thoughts related to those conflicts. They also seek to realize other life values and apply intact aspects of life.

This therapy aims to help couples be aware of their cognitive processes and emotional reactions, either alone or in the relationship, clarify those values that keep them in the relationship, and be committed to acting in ways that consistently fit those goals, even in the presence of unwanted thoughts and feelings [34]. Couples usually avoid situations related to injury, rejection, or conflict. ACT teaches couples to approach their unwanted thoughts and feelings and the relevant physical and communication patterns [35].

In this intervention, the concept of acceptance was taught to couples through metaphors and practice. They were asked to practice it when facing various situations, especially those related to marital problems, and report the results. In the sense that people seek to control their inner events, unacceptance causes psychological inflexibility. After understanding the inefficiency of control and specifying control methods in each couple in the training sessions, the concept of "inclination" was used to replace control, and the relevant exercises were practiced [36].

Being inclined to experiences increased the connection with the present and thus reduced anxiety. The fundamental principles of ACT seek to increase the flexibility of action. These principles include 1) acceptance or the tendency to experience pain or other disturbing events without harnessing them, and 2) values-guided action or commitment combined with the desire to have meaningful personal goals rather than eliminating unwanted experiences. Since verbal methods and cognitive processes are effective when interacting with other non-verbal dependencies and leading to healthy functioning, this method includes exercises based on exposure to linguistic metaphors and methods such as mental care. Therefore, when facing stressful and chal- 
lenging events due to nonjudgmental acceptance, people evaluate them correctly and, in addition, they are on the right track with the commitment they make [37].

The right track includes appropriate behavioral measures in the face of stressful and challenging events. Therefore, value-based practice training (with a desire to act meaningful personal goals before eliminating experiences) helps individuals to value their thoughts and feelings in the face of problems and reduce anxiety, irritability, fear, danger, impatience, and restlessness by dealing with issues while maintaining self-control.

\section{Conclusion}

Acceptance and commitment therapy decreased anxiety, cognitive avoidance, and increased empathy in couples with marital conflicts. ACT can improve empathy in couples involved in marital conflicts. Based on our study results, therapists and counselors are recommended to use ACT to improve marital variables. Researchers can also examine the effectiveness of this approach on other variables of marital life. One of the study's limitations was studying both married men and women, and the researcher could not establish separate groups of males and females. It is suggested to conduct a study on males and females separately or as couples.

\section{Ethical Considerations}

\section{Compliance with ethical guidelines}

The study was approved by the Ethics Committee of Islamic Azad University, Ahvaz Branch (Code: IR.IAU. AHVAZ.REC.1399.019).

\section{Funding}

This article was extracted from the PhD. dissertation of the first author at the Department of Psychology, Ahvaz Branch, Islamic Azad University, Ahvaz.

\section{Authors' contributions}

All authors equally contributed to preparing this article.

\section{Conflict of interest}

The authors declared no conflict of interest.

\section{References}

[1] Bulanda JR, Brown JS, Yamashita T. Marital quality, marital dissolution, and mortality risk during the later life course. Social Science \& Medicine. 2016; 165:119-27. [DOI:10.1016/j.socscimed.2016.07.025] [PMID]

[2] Roshani N, Gholamzadeh Jofreh M, Salehi S. [Comparison of marital satisfaction, marital intimacy, sexual satisfaction and marital adjustment of married persons (various age difference,) with age and duration of marriage control (Persian)]. Journal of Research and Health. 2019; 9(7):64854. [DOI:10.32598/JRH.1566.1]

[3] DeLongis A, Zwicker A. Marital satisfaction and divorce in couples in stepfamilies. Current Opinion Psychology. 2017; 13:158-61. [DOI:10.1016/j.copsyc.2016.11.003] [PMID]

[4] Ghavami BA, Ghanbari Hashem Abad BA, Saffarian MR, Khakpour M. [Effect of Group Cognitive Behavioral Therapy on Inefficient Beliefs and Marital Satisfaction in Pregnant Women With the Fear of First Childbirth (Persian)]. Journal of Research \& Health. 2020; 10(1):11-18. [DOI:10.32598/JRH.10.1.11]

[5] Senaratne R, Van Ameringen M, Mancini C, Patterson $\mathrm{B}$. The burden of anxiety disorders on the family. Journal of Nervous and Mental Diseace. 2010; 198(12):876-80. [DOI:10.1097/NMD.0b013e3181fe7450] [PMID]

[6] Zamani N, Raeisi Z, Zamani S. [Effect of group behavioral activation on depression, anxiety and stress in adjustment: Three-case study (Persian)]. Journal of Research Health. 2019; 9(3):227-35. [DOI:10.29252/jrh.9.3.227]

[7] Hofmann SG. Cognitive factors that maintain social anxiety disorder: A comprehensive model and its treatment implications. Cognnitive Behavioral Therapy. 2007; 36(4):193209. [DOI:10.1080/16506070701421313] [PMID] [PMCID]

[8] Martin RC, Dahlen ER. Cognitive emotion regulation in the prediction of depression, anxiety, stress, and anger. Personality and Individual Differences. 2005; 39(7):1249-60. [DOI:10.1016/j.paid.2005.06.004]

[9] Firouzi R, Tizdast T, Khalatbari J, Ghorban Shiroudi S. [Relationship between stress coping strategies and difficulties in emotion regulation mediated by marital life quality in married women with breast cancer (Persian)]. Journal of Arak University Medical Sciences. 2020; 23(1):34-47. [DOI:10.32598/JAMS.23.1.6005.1]

[10] Cramer D, Jowett S. Perceived empathy, accurate empathy and relationship satisfaction in heterosexual couples. Journal of Social and Personal Relationships. 2010; 27(3):327-49. [DOI:10.1177\%2F0265407509348384]

[11] Hoseinian S, Nooripour R, Afrooz G A. [Effect of mindfulness-based training on aggression and empathy of adolescents at the juvenile correction and rehabilitation center (Persian)]. Journal of Research Health. 2019; 9(6):505-15. [DOI:10.32598/jrh.9.6.505]

[12] Christov-Moore L, Simpson EA, Coudé G, Grigaityte K, Iacoboni M, Ferrari PF. Empathy: Gender effects in brain and behavior. Neurosci Biobehavioral Reviews. 2014; 46 Pt 4(Pt4):604-27. [DOI:10.1016/j.neubiorev.2014.09.001] [PMID] [PMCID] 
[13] Beadle JN, de la Vega CE. Impact of aging on empathy: Review of psychological and neural mechanisms. Frontiers in Psychiatry. 2019; 10:331. [DOI:10.3389/fpsyt.2019.00331] [PMID] [PMCID]

[14] Brinck I. Empathy, engagement, entrainment: The interaction dynamics of aesthetic experience. Cognitive Processing. 2018; 19(2):201-13. [DOI:10.1007/s10339-017-0805-x] [PMID] [PMCID]

[15] Motamedi H, Samavi A, Fallahchai R.[ Effectiveness of group-based acceptance and commitment therapy vs group-based cognitive-behavioral therapy in the psychological hardiness of single mothers (Persian)]. Journal of Research Health. 2020; 10(6):393-402. [DOI:10.32598/ JRH.10.6.1602.2]

[16] Well SA, Fisher P, Myers S, Wheatley J, Patel T, Brewin $\mathrm{CR}$. Metacognitive therapy in treatment-resistant depression: A platform trial. Behaviour Research and Therapy. 2012; 50(6):367-73. [DOI:10.1016/j.brat.2012.02.004] [PMID]

[17] Mirzaeidoostan Z, Zargar Y, Zandi Payam A. [The effectiveness of acceptance and commitment therapy on death anxiety and mental health in women with HIV in Abadan city, Iran (Persian)]. Iranian Journal of Psychiatry and Clinical Psychology. 2019; 25(1):2-13. [DOI:10.32598/ ijpcp.25.1.2]

[18] Haji Eghrari L, Asadi F, Javazi S, Atef Vahid T. [Effectiveness of acceptance and commitment (ACT) therapy on behavioral inhibition and cognitive-behavioral avoidance of women with generalized anxiety disorder (Persian)]. Iranian Journal of Nursing Research. 2019; 13(6):31-8. http:/ / ijnr.ir/article-1-2126-en.html

[19] Amini Naghani S, Najarpourian S, Samavi SA. [Comparing the effectiveness of the triple p-positive parenting program and parenting program of acceptance and commitment therapy on parent-child relationship and self-efficacy of mothers with oppositional defiant disorder children (Persian)]. Journal of Research Health. 2020; 10(2):111-22. [DOI:10.32598/JRH.10.2.7]

[20] Moradzadeh F, Pirkhaefi A. [The effectiveness of acceptance and commitment therapy on marital satisfaction and cognitive flexibility among married employees of the welfare office (Persian)]. Iranian Journal of Psychiatric Nursing. 2018; 5(6):1-7. [DOI:10.21859/ijpn-05061]

[21] Basak Nejad S, Amanollahi A. The effectiveness of an acceptance and commitment-based couple therapy in intimacy and forgiveness among couples. Journal of Family Psychology. 2017; 4(1):41-52. https://www.ijfpjournal.ir/ article_245524.html?lang=en

[22] Afroundeh R, Saidzanozi R. [Comparison of the effect of pilates and traditional corrective exercises on lumbar lordosis in female students (Persian)]. The Scientific Journal of Rehabilitation Medicine, 2017; 6(3):84-94. [DOI:10.22037/ jrm.2017.1100348]

[23] Tomioka M, Shimura M, Hidaka M, Kubo C. The reliability and validity of a Japanese version of symptom checklist 90 revised. BioPsychoSocial Medicine. 2008; 2:19. [DOI:10.1186/1751-0759-2-19] [PMID] [PMCID]
[24] Akhavan Abiri F, Shairi M. [Validity and reliability of symptom checklist-90-revised (SCL-90-R) and brief symptom inventory-53 (BSI-53) (Persian)]. Clinical Psychology and Personality. 2020; 17(2):169-95. [DOI:10.22070/ cpap.2020.2916]

[25] Sexton KA, Dugas MJ. The cognitive avoidance questionnaire: Validation of the English translation. Journal of Anxiety Disorders. 2008; 22(3):355-70. [DOI:10.1016/j. janxdis.2007.04.005] [PMID]

[26] Aghajani S, Samadifard H, Narimani M. [The role of cognitive avoidance components and metacognitive belief in the prediction of quality of life in diabetic patients (Persian)]. Quarterly Journal of Health Psychology. 2017; 6(21):142-56. http://hpj.journals.pnu.ac.ir/article_3705. html?lang=en

[27] Bensalah L, Stefaniak N, Carre A, Besche-Richard C. The basic empathy scale adapted to french middle childhood: Structure and development of empathy. Behaviour Research Methods. 2016; 48(4):1410-20. [DOI:10.3758/s13428015-0650-8] [PMID]

[28] Carré A, Stefaniak N, D’Ambrosio F, Bensalah L, BescheRichard C. The basic empathy scale in adults (BES-A): Factor structure of a revised form. Psychological Assessment. 2013; 25(3):679-91. [DOI:10.1037/a0032297] [PMID]

[29] Farzadi F, Faramarzi H, Shehniyailagh M, Ghasemi, Z. [The causal relationship of perceived pain with marital satisfaction through the mediation of kindness, trust, justice, empathy and forgiveness (Persian)]. Journal of Woman and Family Studies. 2016; 4(2):77-100. [DOI:10.22051/ jwfs.2017.10382.1162]

[30] Hayes SC, Luoma JB, Bond FW, Masuda A, Lillis J. Acceptance and commitment therapy: Model, processes and outcomes. Behaviour Research and Therapy. 2006; 44(1):125. [DOI:10.1016/j.brat.2005.06.006] [PMID]

[31] Khoramnia S, Bavafa A, Jaberghaderi N, Parvizifard A, Foroughi A, Ahmadi M, et al. [The effectiveness of acceptance and commitment therapy for social anxiety disorder: A randomized clinical trial (Persian)]. Trends in Psychiatry and Psychother. 2020; 42(1):30-8. [DOI:10.1590/2237-60892019-0003] [PMID]

[32] Heydari M, Masafi S, Jafari M, Saadat SH, Shahyad S. [Effectiveness of acceptance and commitment therapy on anxiety and depression of razi psychiatric center staff (Persian)]. Open Access Macedonian Journal of Medical Sciences. 2018; 6(2):410-15. [DOI:10.3889/oamjms.2018.064] [PMID] [PMCID]

[33] Biglan A, Hayes SC, Pistorello J. Acceptance and commitment: Implications for prevention science. Prevention Science. 2008; 9(3):139-52. [DOI:10.1007/s11121-008-0099-4] [PMID] [PMCID]

[34] Peterson BD, Eifert GH, Feingold T, Davidson S. Using acceptance and commitment therapy to treat distressed couples: A case study with two couples. Cognitive and Behavioral Practice. 2009; 16(4):430-42.[DOI:10.1016/j.cbpra.2008.12.009] 
[35] Khanjani Veshki S, Shafiabady A, Farzad V, Fatehizade M. [A comparison of the effectiveness of cognitive-behavioral couple therapy and acceptance and commitment couple therapy in the couple's conflict in the city of Isfahan (Persian)]. Jundishapur Journal of Health Sciences. 2017; 9(3):e43085. [DOI:10.5812/jjhs.43085]

[36] Farahanifar M, Heidari H, Davodi H, Aleyasin SA. [The effect of acceptance and commitment therapy on the conflict resolution styles of incompatible marital women (Persian)]. International Archives of Health Sciences. 2019; 6(2):101-7. http:/ /oldiahs.kaums.ac.ir/article-1-245-en.html

[37] Ghafoorian P, Hasanabadi H. [Effectiveness of acceptance and commitment therapy on thought control and meta cognitive beliefs among females experienced extramarital affairs trauma (Persian)]. International Journal of Womens Health Wellness. 2016; 2:020. [DOI:10.23937/24741353/1510020] 
This Page Intentionally Left Blank 